металоксидных нелинейных ограничителей перенапряжений на персональных компьютерах.

Ключевые слова: нелинейный ограничитель перенапряжений, остающееся напряжение, коммутационный импульс тока, кусочная функция.

Trotsenko Yevgeniy, PhD, Associate Professor, Department of High Voltage Engineering and Electrophysics, National Technical University of Ukraine «Igor Sikorsky Kyiv Polytechnic Institute», Ukraine, e-mail:y.trotsenko@kpi.ua, ORCID: http://orcid.org/00000001-9379-0061
Brzhezitsky Volodymyr, Doctor of Technical Sciences, Professor, Department of High Voltage Engineering and Electrophysics, National Technical University of Ukraine «Igor Sikorsky Kyiv Polytechnic Institute», Ukraine, e-mail: v.brzhezitsky@kpi.ua, ORCID: http:// orcid.org/0000-0002-9768-7544

Masluchenko Igor, PhD, Associate Professor, Department of High Voltage Engineering and Electrophysics, National Technical University of Ukraine «Igor Sikorsky Kyiv Polytechnic Institute», Ukraine, e-mail:i.masluchenko@kpi.ua,ORCID: http://orcid.org/0000-00016073-9649

\section{Ostroverkhov M.,} Silvestrov A., Kryvoboka G.

\title{
IDENTIFICATION OF THE PARAMETERS OF THE CABLE PRODUCTION PROCESS
}

\begin{abstract}
Завдяки можливостям сучасних інформаційних систем показано шляхи удосконалення систем параметричної ідентифікачії, а саме, отримання більш точних очінок параметрів математичної моделі досліджуваного об'єкта з обмежених у часі і діапазоні, зашумленних вибірок даних. Розглянутий метод ідентифікаиї запропоновано використовувати в адаптивних системах керування процесом виготовлення високовольтних електричних кабелів.
\end{abstract}

Ключові слова: параметрична ідентифікація, інтегрований метод ідентифікаціі, електротехнічні системи, електричні кабелі.

\section{Introduction}

Technologically, leading countries transferred or are transferring to the transmission of electricity using ultrahigh-voltage cables with polymer insulation. Cable production is carried out on continuous technological lines under the influence of many destabilizing factors: transport delays, measurement noise, impossibility of exact coordination of operation of all systems, fluctuations in raw material parameters and various physical and mechanical properties of cable components.

Obtaining objective information about the parameters and the course of the technological process makes it possible to improve the quality of the systems of optimal control, diagnostics and forecasting. A significant amount of scientific research has been devoted to the problem of parametric identification in the industrial production of cables [1-13]. However, in the modern theory of identification there is a significant gap between the theoretical part and the real situation. Owing to the natural nonstationarity of the processes, the large number theorem in practice is often not fulfilled, and in conditions of limited sampling, statistically optimal identification methods can lose not only optimality, but also correctness.

Thus, it is urgent to improve the methods of parametrical identification of the technological process of cable production and their introduction in adaptive optimal control systems. This will improve the quality of products in real conditions of parametric and signal uncertainty and will promote wider use of high-voltage cable with polymer insulation in the electricity industry.

\section{The object of research and its technological audit}

The object of research is the process of producing electric cables with polymer insulation for ultrahigh voltages.

Manufacture of cables with XLPE insulation is carried out on electrical complexes consisting of dozens of local systems interconnected via mobile cable products under the conditions of many undetermined disturbing factors [1-3]. The application of polyethylene insulation to a conductive core that moves at a speed of about $50 \mathrm{~m} / \mathrm{min}$ is carried out using a unit of three extruders 1 (Fig. 1). The outer diameter of each insulation layer is measured with random noise by the X-ray sensor unit 2 at a distance of about $0.5 \mathrm{~m}$ from the exit of the extruders (Fig. 1). The thickness of each layer of insulation is regulated by automated electric drives of extruders by changing the rotation speed of worms.

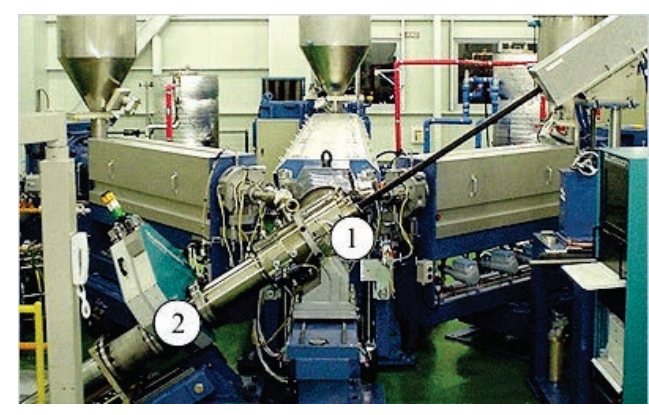

Fig. 1. Units: 1 - extruders; 2 - sensors 
Improving the quality of control in the presence of noise measurements based on the concept of targeted identification [4] is an important task and for this system helps to reduce the radial and axial displacement of insulation relative to metal living during its multi-layer application. The scheme of the system for controlling the thickness (outer diameter) of the insulation layers under the conditions of destabilizing factors is shown in Fig. 2.

In Fig. 2: $X_{d}, X(t), X\left(t-t_{d}\right)$ - vector functions of given, actual, measured and predicted diameters;

$\Delta X(t), U(t), \omega(t)$ - vector functions of errors in the regulation of diameters, control actions and rotation speeds of worms of three extruders;

$N_{1}(t), N_{2}(t)$ - vector functions of the noise measurements of the extruder speeds and the diameters of the insulation layers;

$\beta(t)$ - vector function of the identified parameters of the mathematical model of the connection $\omega(t)$ and $X(t)$.

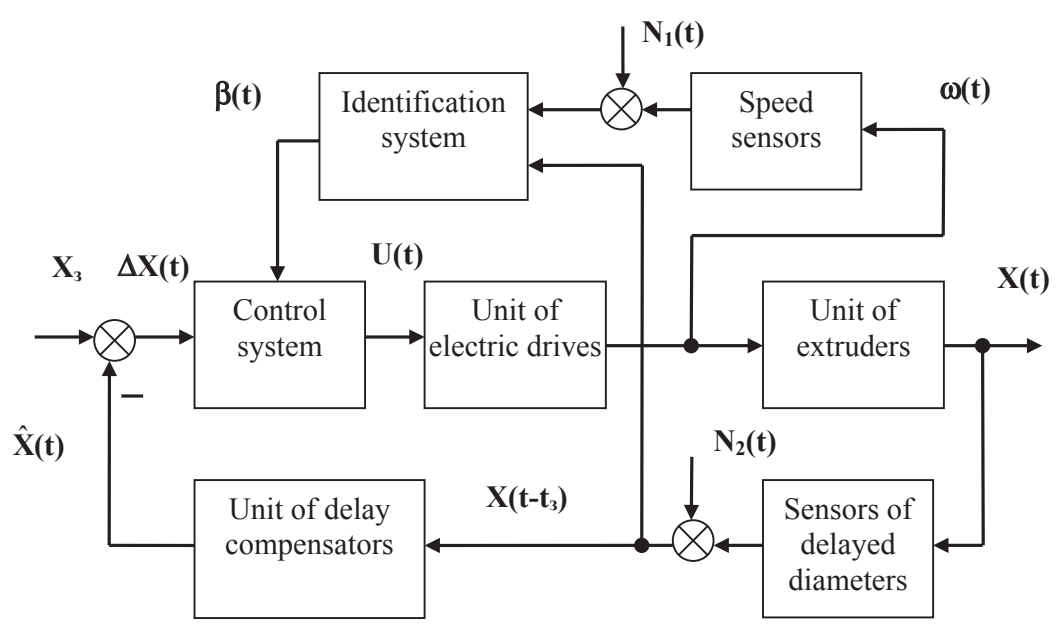

Fig. 2. Functional diagram of the insulation thickness stabilization system

\section{Research of existing solutions of the problem}

The identification theory establishes a mathematical model (MM) of the connection between the input variables of the investigated object $\omega(t)$ (causes, independent regressors, control actions) and output $X(t)$ (effects, dependent variables) by observing the behavior of the object in the passive or active experiment mode. Over the past century, there has been a significant development of methods and means of identification [6,7], which use modern electronic systems for data collection and processing (EDPS). This allowed to significantly increase the frequency of polling of sensors, the speed and accuracy of information processing, to increase the information content of data in time-limited samples. However, the natural properties of real objects (the continuity of matter and motion, the universal interconnection of everything with everything) do not allow to obtain MMs, which are identical (isomorphic) to the real object. The real object is not the autonomy, not the stationarity, but not the linearity of the interrelationships of the state variables, the infinite dimensionality, etc. The best EDPS is able to observe a limited set of state variables $X(t)$ of the object in a limited range. Therefore, the MM only approximates the interconnection of the components $x_{i}(t), \quad i=\overline{1, n}$, the $n$-dimensional vector of the function $X(t)$ and the vector function $U(t)$ of the input (control) actions bounded in dimension $m$ :

$$
\dot{X}^{*}(t)=f\left(X^{*}(t), U^{*}(t), t\right),
$$

where $\dot{X}^{*}(t)$ - vector function of speed change $X^{*}(t)$.

One of the most problematic places in the cable production process is the presence in the loops of insulation thickness regulation a time delay $t_{d}$ of about $0.5 \mathrm{~s}$ and noise measurements of the speeds of worms and the diameters of the insulation layers. The temporal delay negatively affects the accuracy of controlling the thickness of the layers and can lead to a loss of system stability, and the noisiness of useful signals causes a decrease in the accuracy and speed of regulation [5].

\section{The aim and objectives of research}

The aim of research is increase of the accuracy of applying multi-layer polymer insulation of the technological process to the manufacture of a high-voltage cable in real conditions of uncertainty of the control object characteristics on the basis of the parametric identification method.

To achieve this aim, it is necessary to perform the following tasks:

1. To develop a method of parametric identification, which in real conditions of noisy measurements of variables of the control object would give an estimate close to the exact values of the parameters.

2. To conduct studies on the properties of the proposed method of parametric identification in comparison with the traditional least squares method.
In such conditions, the requirements to the systems of identification and management of industrial facilities have changed [4, 8-13]: the coordinated implementation of the functions of identification and management; use of current operational data of the facility; accounting features of the structure of the object; identification with obtaining estimates of coefficients with the necessary statistical properties; multivariate identification with obtaining of several variants of differed-time estimates; general achievement of research and production goals of operation; purposeful hierarchically constructed, structural-parametric identification.

One of the ways to solve the problem can be methods, considered in [4, 8, 10-13]. Under conditions of limited deviations $\Delta X^{*}, \Delta U^{*}$ from the basic mode $\left(X_{0}, U_{0}\right)$, time $t$, and the presence of the natural smoothness of the map $f$, the nonlinear nonstationary model (1) can be represented by an admissible error $\varepsilon^{*}(t)$ by a linear stationary system [4]:

$$
\Delta \dot{X} *(t)=A_{0} X^{*}(t)+B_{0} U^{*}(t)+\varepsilon^{*}(t)
$$

or their scalar representation:

$$
\begin{aligned}
& \Delta \dot{x}_{i}^{*}(t)=\sum_{j=1}^{n} a_{i j} \Delta x_{j}{ }^{*}(t)+\sum_{k=1}^{m} b_{i k} \Delta U_{k}{ }^{*}(t)+\varepsilon_{i}{ }^{*}(t), \\
& i=\overline{1, n} .
\end{aligned}
$$


The task of parametric identification consists in determining the estimates $\hat{a}_{i j}, \hat{b}_{i k}$ of the coefficients $a_{i j}, b_{i k}$ with a minimum of the error $\varepsilon_{i} *(t)$ functional $I_{i}$. It is logical to take as the average square error $\varepsilon_{i}{ }^{*}(t)$ in the interval $T$ of observation as $I_{i}$, where the exact values of the corresponding variables appear in (1)-(3) [4]. Then, as the best model (2), there will be one whose coefficients $a_{i j}, b_{i k}$ are calculated by the least squares method for the exact data, $\dot{X}^{*}(t), X^{*}(t), U^{*}(t)$. If in EDPS there is a possibility to directly measure $X^{*}(t), U^{*}(t)$ or calculate $\dot{X}^{*}(t)$, then formally dynamic models (2), (3) can be represented as regression ones. For example, each $i$-th line of system (2) is represented as:

$$
y^{*}(k)=\sum_{i=1}^{n+m} \beta_{i} x_{i}^{*}(k)+\varepsilon^{*}(k),
$$

where $y^{*}(k)=\Delta \dot{x}_{i}^{*}(k), x_{i}^{*}(k)$ includes a set $\Delta x_{j}^{*}(k), \Delta U_{k} *(k)$; $\beta_{i}$ includes $a_{i j}, b_{i k}$ in equation (3); $k$ - the number of the discrete $t_{k}$ of time $t, k=\overline{1, m}$.

Theoretically, the best estimate of the vector $\beta$ of the parameters $a_{i j}, b_{i k}$ will be the LS estimate for accurate measurement of variables:

$$
\widehat{\beta}^{*}=\left(\left(X^{*}\right)^{T} X^{*}\right)^{-1}\left(X^{*}\right)^{T} Y^{*} .
$$

Thus, the results of the analysis of identification methods allow to conclude that the achievement of the aim of the work is possible when using methods of targeted structural-parametric identification [4]. The problem consists in constructing a parametric identification method that would give an estimate $\widehat{\beta}$ close to the least squares estimate (5) for accurate data in real conditions of noisy measurements $X^{*}(t), Y^{*}(t)$ of object variables.

\section{Methods of research}

In practice, the least squares estimate must be obtained from measurements disturbed by random obstacles $N_{x}$ and $N_{y}$ :

$$
X=X^{*}+N_{x} ; \quad Y=Y^{*}+N_{y} .
$$

Least squares estimate (5) $\widehat{\beta}$ of the vector $\beta^{*}$ for real data (6):

$$
\widehat{\beta}=\left(X^{T} X\right) X^{T} Y=C Y, C=\left(X^{T} X\right) X^{T} .
$$

Let's suppose that the obstacles $N_{x}$ and $N_{y}$ are Gaussian white noise-canceling noise and calculate the displacement $\Delta \beta$ of the estimate (7) with respect to the exact value (5):

$$
\begin{aligned}
& \Delta \beta=M\{\widehat{\beta}\}-\beta^{*}=M\left\{\left[C^{*}+\delta C(N)\right]\left[Y^{*}+\varepsilon^{*}+N_{y}\right]\right\}-\beta^{*}= \\
& =M\left\{\left[C^{*}+\delta C(N)\right] Y^{*}\right\}-\beta^{*}= \\
& =\left[X^{*} T X^{*}+M\left\{N_{x}^{T} N_{x}\right\}\right]^{-1} X^{*} T Y^{*}-\beta^{*}= \\
& =\left[X^{*} X^{*}+\operatorname{diag} \sigma_{i}^{2}\right]^{-1} X^{*} Y^{*}-\beta^{*} .
\end{aligned}
$$

Let's introduce the notation:

$$
\begin{aligned}
& X^{* \mathrm{~T}} X^{*}=A^{*}, M\left\{N^{\mathrm{T}}{ }_{x} N_{x}\right\}=\delta A, \\
& X^{* \mathrm{~T}} Y^{*}=B^{*}=M\left\{X^{T} Y\right\}=B,
\end{aligned}
$$

then

$$
\left(A^{*}\right)^{-1} B^{*}=\widehat{\beta}^{*},\left[A^{*}+\delta A\right] \widehat{\beta}=B^{*},
$$

hence

$$
\delta A \widehat{\beta}=-A^{*}\left(\widehat{\beta}-\beta^{*}\right)=-A^{*} \Delta \widehat{\beta},
$$

so

$$
\delta A\left(\beta^{*}+\Delta \widehat{\beta}\right)=-A^{*} \Delta \widehat{\beta}
$$

or

$$
\Delta \widehat{\beta}=-\left(A^{*}+\delta A\right)^{-1} \delta A \beta^{*} .
$$

The estimate (7) is shifted relative to the true $\beta^{*}$ by the value (9). Assuming that the norm $\|\delta A\| \rightarrow 0$, $\hat{\beta}$ tends to $\beta^{*} ; \Delta \widehat{\beta} \rightarrow 0$, under the condition $\|\delta A\| \rightarrow \infty$ the estimate $\hat{\beta}$ tends to zero, and $\Delta \widehat{\beta}$ to $-\beta^{*}$. The covariance of the estimate (7) under the conditions given above, and assuming that the norm $\left\|N_{x}^{\mathrm{T}} \varepsilon\right\|$ is much less than $\left\|X^{* \mathrm{~T}}\right\|$ or $\left\|N_{x}^{\mathrm{T}} Y^{*}\right\|$ is approximately equal to [8]:

$$
\begin{aligned}
& \operatorname{cov}[\widehat{\beta}] \cong M\left\{\left[C_{1} \varepsilon+C_{2} N_{\%}\right]\left[C_{1} \varepsilon+C_{2} N_{x}\right]^{T}\right\} \\
& =C_{1} M\left\{\varepsilon \varepsilon^{T}\right\} C_{1}{ }^{T}+C_{2} M\left\{N_{X} N^{T}{ }_{X}\right\} C_{2}{ }^{T},
\end{aligned}
$$

where $\varepsilon=\varepsilon^{*}+N_{Y}$

$$
\begin{aligned}
& C_{1}=\left[X^{*} T X^{*}+M\left\{N_{X} N_{X}^{T}\right\}\right]^{-1} X^{*} T, \\
& C_{2}=\left[X^{*} T X^{*}+M\left\{N_{X} N_{X}^{T}\right\}\right]^{-1} Y^{* T} .
\end{aligned}
$$

The first component of expression (10) decreases with increasing $N_{x}$, in the second, $C_{2}$ decreases, but $M\left\{N_{X} N_{X}^{T}\right\}$ increases. But $C_{2}$ enters the expression (10) quadratically, whereas $M\left\{N_{X} N_{X}^{T}\right\}$ - linearly. Therefore, for white noise, if $M\left\{N_{X} N_{X}^{T}\right\}=\sigma_{N x}^{2}$, with increasing $\sigma_{N x}^{2}$ covariance of the $\widehat{\beta}$ estimate decrease. Thus, least squares method under the conditions (6) has a regularization property, similar to Tikhonov regularization. The latter consists in minimizing the functional:

$$
I=\varepsilon^{B} \varepsilon=\left(Y-X^{*}\right)^{T}\left(Y-X^{*}\right)+\alpha \widehat{\beta}^{T} \widehat{\beta},
$$

where $\alpha$ - the regularization parameter.

With the necessary minimum condition for the expression (11):

$$
\frac{\partial I}{\partial \widehat{\beta}}=0=2\left(X^{*} T X^{*} \widehat{\beta}-X^{*} Y+\alpha \widehat{\beta}\right),
$$

let's obtain a somewhat lower in norm $\|\widehat{\beta}\|$, but a regularized least squares estimate:

$$
\widehat{\beta}=\left(X^{* T} X^{*}+\alpha I\right)^{-1} X^{* T} Y \text {. }
$$

Thus, comparing (8) and (13), it is possible to see that in the least squares Tikhonov parameter is equal to diag $\sigma_{i}{ }^{2} \cdot M$. The least squares estimate (7) are found as the coordinate of the minimum point of the functional $\varepsilon^{T} \varepsilon$. Since the functional is a square of $\varepsilon$, which is a mixture of a useful signal $Y^{*}-X^{*} \beta$ and a random perturbation 
$N_{y}-N_{x} \beta$, averaged over a finite interval $T$, then, as a function of $\beta$, it is not exact. Therefore, the operation of differentiating $\frac{\partial}{\partial \beta}\left(\varepsilon^{T} \varepsilon\right)$ a noisy function $\varepsilon^{T} \varepsilon$ is incorrect [4]. This is due to the low accuracy of least squares estimates on short, highly noisy samples of the $Y$ data, even for exact $X^{*}$.

\section{Research results}

To improve the quality of identification, it is desirable to reduce the spread of the values of the functional $I$, almost without reducing its curvature and the coordinates of the extremum. This can be done by additional averaging over the set of quasi-statistically independent functionals close to the mean square value for the exact data [4]. Such functional can be mean products $\frac{1}{T} \int_{0}^{\mathrm{T}} \varepsilon(t) \varepsilon(t+\theta) \mathrm{d} t$ shifted in time $t$ to the interval $\theta$. Averaging them in the interval $\left[-\tau_{1}, \tau_{1}\right]$, let's obtain the following functional:

$$
I=\frac{1}{2} \int_{-\tau_{2}}^{\tau_{1}} \eta(\theta) \int_{0}^{T} \varepsilon(t) \varepsilon(t+\theta) \mathrm{d} t \mathrm{~d} \theta,
$$

where $\eta(\theta)$ - weight function.

From the necessary condition for a minimum with respect to $\beta_{k}, k=\overline{1, n}$ of the exponent (14):

$$
\begin{aligned}
& \frac{\partial I}{\partial \beta_{k}}=\frac{1}{2} \int_{-\tau_{1}}^{\tau_{1}} \eta(\theta) \int_{0}^{T}\left[\frac{\partial \varepsilon(t)}{d \beta_{k}} \varepsilon(t+\theta)+\varepsilon(t) \frac{\partial \varepsilon(t+\theta)}{\partial \beta_{k}}\right] \mathrm{d} t \mathrm{~d} \theta= \\
& =\int_{-\tau_{1}}^{\tau_{1}} \eta(\theta) \int_{0}^{T}\left(-x_{k}(t)\right)\left[y(t+\theta)-\sum_{i=1}^{n} \beta_{i} x_{i}(t+\theta)\right]+ \\
& +\left(-x_{k}(t+\theta)\right)\left[y(t)-\sum_{i=1}^{n} \beta_{i} x_{i}(t)\right]=0, k=\overline{1, n} ;
\end{aligned}
$$

let's obtain a system of equations:

$$
A \cdot \widehat{\beta}=B
$$

where $A$ - the matrix $n \times n$ with elements $a_{i k} ; B$ - matrixcolumn $n \times 11$ with the elements $b_{k}$ :

$$
\begin{aligned}
& a_{i k}=\int_{-t_{1}}^{t_{1}} \eta(\theta) \int_{0}^{T}\left[\left(x_{i}(t+\theta)\right) x_{k}(t)+x_{i}(t) x_{k}(t+\theta)\right] \mathrm{d} t \mathrm{~d} \theta, \\
& b_{k}=\int_{-t_{1}}^{t_{1}} \eta(\theta) \int_{0}^{T}\left[\left(y_{i}(t+\theta)\right) x_{k}(t)+y(t) x_{k}(t+\theta)\right] \mathrm{d} t \mathrm{~d} \theta .
\end{aligned}
$$

For discrete in time $t_{j}$ samples, the integrals are replaced by the sums. Then:

$$
\begin{aligned}
& a_{i k}=\sum_{1=-p}^{p} \eta(l) \sum_{j=1}^{M}\left[\left(x_{i}(j+l)\right) x_{k}(j)+x_{i}(j) x_{k}(j+l)\right], \\
& b_{k}=\sum_{1=-p}^{p} \eta(l) \sum_{j=1}^{M}\left[(y(j+l)) x_{k}(j)+y(j) x_{k}(j+l)\right] .
\end{aligned}
$$

The solution of system (16) gives the required estimate $\hat{\beta}$ :

$$
\widehat{\beta}=A \cdot B \text {. }
$$

The weight function $\eta(m)$ can be found in the class of finite functions that are symmetric with respect to $m=0$ (such that $\eta(0)=\eta\left( \pm m_{c r}\right)=0$ ). For example:

$$
\eta(m)=\eta(m, \gamma, \theta)=(1+|m|)^{\theta}\left(1-\cos \frac{|\pi m|}{m_{c r}}\right)^{\gamma},
$$

where $\theta \in( \pm \infty), \gamma \in(0, \infty), m_{c r}$ is determined when:

$$
\operatorname{det}\left[X^{T}\left(X_{m_{c r}}+X_{-m_{\text {cr. }}}\right)\right] \cong 0 \text {. }
$$

The parameters $\theta$ and $\gamma$ are optimized for the main (external) exponent $I[6,11]$. The parameter $\gamma$ affects the width of the pulse $\eta(m)$, and $\theta$ its asymmetry relative to the maximum (Fig. 3).

A theoretical analysis of the unbiasedness and effectiveness of the estimates (16) is given in [6], a numerical analysis is considered below on a concrete example.

The quality of parametric estimation, that is, the solution of the inverse problem of mathematics [10], is affected by the degree of interrelation of the variables $x_{i}(t)$, $i=\overline{1, n}$ and not by their number. Therefore, let's confine ourselves to a simple example. The relation between $\omega^{*}(t)$ and $X^{*}(t)$ (Fig. 2):

$$
x^{*}\left(t-t_{d}\right)=k \omega *(t),
$$

where $t_{d}$ - an approximately known value of the delay in the measurements $x^{*}(t)$.

If the operator $e^{-p t_{d}}=1 / e^{p t_{d}}$ is expanded in series and limited (due to a small $t_{d}$ with respect to the period of the change in the useful signal) by the first terms, that is:

$$
e^{-p t_{d}} \cong 1+t_{d} p,
$$

then, returning to the expression (20) in time, let's obtain the equation:

$$
\frac{d \omega^{*}}{d t}=\beta_{1}^{*} \omega^{*}(t)+\beta_{2}^{*} x^{*}(t)
$$

where $\beta_{1}^{*}=-\frac{1}{t_{d}}, \quad \beta_{2}^{*}=-\frac{1}{t_{d} \cdot k}$.

Equation (22) can be represented in the form (4), where $y^{*}=\frac{d \omega^{*}}{d t}, \quad x_{1}^{*}=\omega^{*}, x_{2}^{*}=x^{*}, \quad \beta_{1}^{*}=\beta_{2}^{*}=1$ :

$$
\begin{aligned}
& y^{*}(k)=\beta_{1} * x_{1} *(k)+\beta_{2} * x_{2} *(k) ; k=\overline{1,1000} \\
& \beta_{1}^{*}=\beta_{2}{ }^{*}=1 ; x_{1}{ }^{*}=\sin \frac{\pi k}{500} ; x_{2}{ }^{*}=\sin \left(\frac{\pi k}{500}+\frac{\pi}{6}\right) .
\end{aligned}
$$

On measurements $y(k), x_{1}(k), x_{2}(k)$, white noise is imposed - random numbers with uniform distribution in the range [ \pm 1$]$. For an objective estimation of the displacement and spread of estimates $\widehat{\beta}_{1}, \widehat{\beta}_{2}$ relative to true $\beta_{1}$, $\beta_{2}, 10$ statistically independent realizations of noise are generated. The results of identifying the coefficients $\beta_{1}$, $\beta_{2}$ for the least squares method and the proposed method are given in Table 1. 


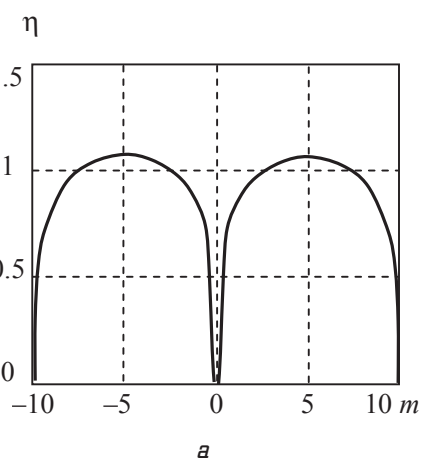

$\eta$

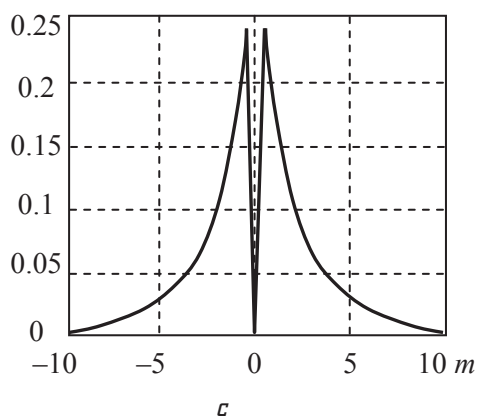

$\eta$

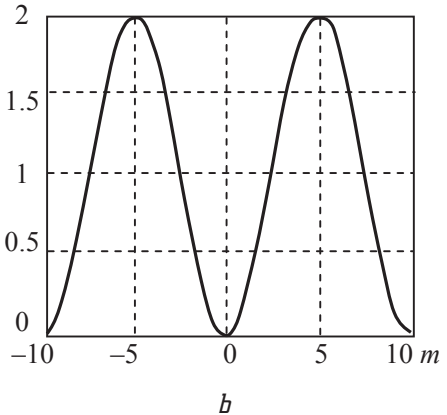

$\eta$

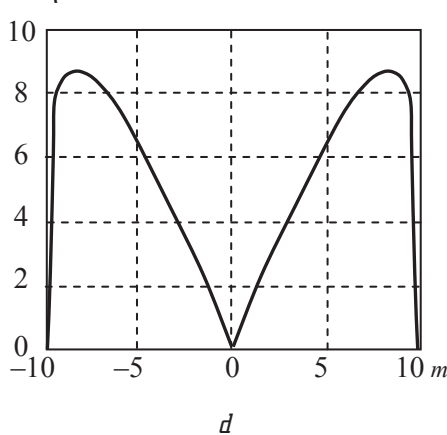

Fig. 3. Dependence $\eta(m, \theta, \gamma)$ : $a-\theta=0, \gamma=0.1 ; b-\theta=0, \gamma=1 ; c-\theta=2, \gamma=0.1 ; d-\theta=2, \gamma=0.1$

Table 1

The results of estimating the parameters for noisiness of input and output variables

\begin{tabular}{|c|c|c|c|c|}
\hline \multirow{2}{*}{ No. } & \multicolumn{2}{|c|}{ Least squares method } & \multicolumn{2}{|c|}{$\begin{array}{l}\text { Estimations by the } \\
\text { proposed method }\end{array}$} \\
\hline & $\widehat{\beta}_{1}$ & $\hat{\beta}_{2}$ & $\widehat{\beta}_{1}$ & $\widehat{\beta}_{2}$ \\
\hline 1 & 0.479064 & 0.498144 & 1.028277 & 0.909424 \\
\hline 2 & 0.460761 & 0.449362 & 1.017960 & 0.884437 \\
\hline 3 & 0.484336 & 0.566314 & 1.091629 & 0.8435981 \\
\hline 4 & 0.502460 & 0.540129 & 1.002014 & 0.929065 \\
\hline 5 & 0.524662 & 0.465954 & 1.031359 & 0.979809 \\
\hline 6 & 0.499727 & 0.505891 & 1.290496 & 0.743785 \\
\hline 7 & 0.484993 & 0.525599 & 0.709392 & 1.230719 \\
\hline 8 & 0.491984 & 0.443124 & 0.828313 & 1.191077 \\
\hline 9 & 0.467612 & 0.485666 & 1.082564 & 0.719709 \\
\hline 10 & 0.464255 & 0.601529 & 0.965397 & 1.011236 \\
\hline $\bar{\beta}$ & 0.4860 & 0.5082 & 1.0047 & 0.943 \\
\hline$\sigma_{\beta i}^{2}$ & 0.00038 & 0.0026 & 0.0241 & 0.0283 \\
\hline$\sigma_{\beta_{i}}$ & 0.0197 & 0.0511 & 0.1551 & 0.1682 \\
\hline
\end{tabular}

The results of estimating the parameters in the situation of noisiness of only the original variables by the proposed method and least squares method are presented in Table 2.

As can be seen from Table 1 , and $\beta_{1}$ and $\beta_{2}$ for least squares method are on average underestimated by $50 \%$ (9). However, the regularization (13) takes place: the spread $\sigma_{\beta i}$ of estimates is 0.02 and 0.05 . In the proposed method (Table 1), the estimates are almost unchanged: 1.005 and 0.943 , but the spread is greater than in the regularized

least squares method $(0.15,0.16)$. Reducing the spread is possible due to a compromise between displacement and dispersion by changing the parameters $\theta$ and $\gamma$ of the weight function $\eta(\theta)$. In the case of noise only in the original variable (Table 2) (ideal situation for least squares method), the estimates are unbiased, but the spread of the estimates for this method $(0.07$ and 0.09$)$ is greater than the spread $(0.05$ and 0.08 ) optimization of parameters $\theta$ and $\gamma$ of the function $\eta(m)$. In the case that there is an opportunity to optimize $\eta(m)$, the gain of the proposed method in the sense of unbiasedness and the effectiveness of estimates relative to least squares method is much larger.

Table 2

The results of estimating the parameters with noisiness of only the original variables

\begin{tabular}{|c|c|c|c|c|}
\hline \multirow{2}{*}{ No. } & \multicolumn{2}{|c|}{ Least squares methad } & \multicolumn{2}{|c|}{$\begin{array}{c}\text { Estimations by the } \\
\text { proposed method }\end{array}$} \\
\cline { 2 - 5 } & $\hat{\beta}_{1}$ & $\hat{\beta}_{2}$ & $\hat{\beta}_{1}$ & $\hat{\beta}_{2}$ \\
\hline 1 & 0.978163 & 0.921239 & 0.949749 & 1.101904 \\
\hline 2 & 1.054159 & 0.937174 & 1.023444 & 0.855408 \\
\hline 3 & 0.932957 & 1.081755 & 0.982595 & 1.061898 \\
\hline 4 & 1.118181 & 0.881928 & 1.011197 & 0.913209 \\
\hline 5 & 0.984799 & 1.032784 & 1.190762 & 0.980720 \\
\hline 6 & 1.000925 & 1.019233 & 1.101843 & 0.982305 \\
\hline 7 & 1.154927 & 0.825866 & 0.986680 & 1.124493 \\
\hline 8 & 0.940740 & 1.076540 & 1.021694 & 0.987923 \\
\hline 9 & 0.957818 & 1.082379 & 0.963915 & 1.086121 \\
\hline 10 & 1.000738 & 0.941259 & 1.096120 & 0.994633 \\
\hline $\bar{\beta}$ & $\mathbf{1 . 0 1 2 3}$ & $\mathbf{0 . 9 8 0 0}$ & $\mathbf{1 . 0 2 8 0}$ & $\mathbf{1 . 0 0 8 9}$ \\
\hline$\sigma_{\beta i}^{2}$ & $\mathbf{0 . 0 0 5 5}$ & $\mathbf{0 . 0 0 8 3}$ & $\mathbf{0 . 0 0 2 7}$ & $\mathbf{0 . 0 0 7 3}$ \\
\hline$\sigma_{\beta_{i}}$ & $\mathbf{0 . 0 7 4 4}$ & $\mathbf{0 . 0 9 1 1}$ & $\mathbf{0 . 0 5 2 2}$ & $\mathbf{0 . 0 8 5 4}$ \\
\hline
\end{tabular}

\section{SWOT analysis of research results}

Strengths. The proposed method for identifying the parameters of the technological process of multi-layer application of high-voltage cable insulation in real conditions of noisy measurements of control object variables in contrast to the traditional least squares method gives an estimate of parameters that is close to the exact values of the parameters. The introduction of the method will improve the accuracy of applying layers of polymer cable insulation to ultrahigh voltage.

Weaknesses. The developed method for identifying the parameters of the technological process of multi-layer application of insulation of a high-voltage cable has not been tested in the current production facility, which has a continuous technological cycle. Conducting research in production is associated with additional financial and material costs.

Opportunities. A promising direction for further research is the creation of a common method of operational identification for object control based on a purposeful hierarchically constructed identification system as an auxiliary function with respect to the main functional goal 
in problems of adaptive optimal control, diagnostics and forecasting. Improving the quality of the cable by stabilizing technological parameters, estimating the values of technological indicators, predicting the values of parameters and technological variables, reducing the radial and axial displacement of insulation relative to the metal lived during its multilayer application, reducing the longitudinal vibrations of metal living in the process of displacement will contribute to its wider implementation in electric power industry of Ukraine and other countries of the world.

Threats. The equipment and software of automated control systems for technological lines for production of high-voltage cables with polymer insulation is made by several well-known foreign companies. The introduction of the research results is connected with the additional costs of the enterprise for the correction of the software of the existing automated control system.

\section{Conclusions}

1. A method for identifying process parameters for multi-layered insulation is developed. In the actual conditions of noisy measurements of control object variables, unlike the traditional least squares method, an ultrahighvoltage cable gives an estimate close to the exact values of the parameters. The introduction of the method will improve the accuracy of applying layers of polymer cable insulation.

2. Analysis of the research results shows that the proposed method allows in a real situation of noisy measurements of the input and output signals of primary converters to obtain unbiased estimates of parameters close to the estimates for least squares for accurate measurements. In the case of noise only in the initial variables (ideal situation for least squares method), the estimates are unbiased, but the spread of the estimates for least squares method (0.07 and 0.09) is greater than the variance of the estimates in the proposed method (0.05 and 0.08). This makes it possible to effectively use it in systems of adaptive control of the thickness of layers of polymer insulation in the production of cables for ultrahigh voltages.

\section{References}

1. Shidlovskii, A. K. Kabeli s polimernoi izoliatsiei na sverhvysokie napriazheniia [Text]: Monograph / A. K. Shidlovskii, A. A. Shcherba, V. M. Zolotarev, A. D. Podoltsev, I. N. Kucheriavaia. - Kyiv: Institute of Electrodynamics of the National Academy of Sciences of Ukraine, 2013. - 551 p.

2. Vahedy, V. Polymer insulated high voltage cables [Text] / V. Vahedy // IEEE Electrical Insulation Magazine. - 2006. Vol. 22, No. 3. - P. 13-18. doi:10.1109/mei.2006.1639025

3. Bikineeva, Yu. L. Integrirovannaia sistema avtomatizatsii kabel'nogo proizvodstva [Text] / Yu. L. Bikineeva, E. I. Gromakov, V. M. Pavlov, A. M. Malyshenko // Bulletin of the Tomsk Polytechnic University. Geo Assets Engineering. - 2009. Vol. 314, No. 5. - P. 69-74.

4. Silvestrov, A. M. Systemy i metody identyfikatsii elektrotekhnichnykh obiektiv [Text]: Monograph / A. M. Silvestrov, M. Ya. Ostroverkhov, O. M. Skrynnik. - Kyiv: National Academy of Sciences of Ukraine, 2016. - 324 p.
5. Egupov, N. D. Metody klassicheskoi i sovremennoi teorii avtomaticheskogo upravleniia [Text] / ed. by N. D. Egupov. Moscow: MSTU n. a. N. E. Bauman, 2000. - 748 p.

6. Walter, E. Identification of Parametric Models from Experimental Data [Text] / E. Walter, L. Pronzato. - London: Communications and Control Engineering, 1997. - 413 p.

7. Ljung, L. System Identification: Theory for the User [Text] / L. Ljung. - Ed. 2. - Prentice Hall, 1999. - 672 p.

8. Nelles, O. Nonlinear System Identification [Text] / O. Nelles. Berlin, Heidelberg: Springer, 2001. - 785 p. doi:10.1007/ 978-3-662-04323-3

9. Pintelon, R. System Identification: A Frequency Domain Approach [Text] / R. Pintelon, J. Schoukens. - Ed. 2. - WileyIEEE Press, 2012. - 788 p. doi:10.1002/9781118287422

10. Kuz'menko, A. A. Nonlinear adaptive control of a shipboard power plant turbine [Text] / A. A. Kuz'menko // Journal of Computer and Systems Sciences International. - 2012. Vol. 51, No. 4. - P. 512-525. doi:10.1134/s1064230712030069

11. Billings, S. A. Nonlinear System Identification: NARMAX Methods in the Time, Frequency, and Spatio-Temporal Domains [Text] / S. A. Billings. - Wiley, 2013. - 574 p. doi:10.1002/9781118535561

12. Ginsberg, K. S. The problem of structure identification for the purpose of design of an automatic control system [Text] / K. S. Ginsberg // Proceedings of the X International Conference «System Identification and Control Problems. SICPRO‘15». Moscow, January 26-29, 2015. - P. 43-80.

13. Ljung, L. System Identification Toolbox. Getting Started Guide [Text] / L. Ljung. - The MathWorks, Inc., 2017. - 226 p.

\section{ИДЕНТИФИКАЦИЯ ПАРАМЕТРОВ ПРОЦЕССА ПРОИЗВОДСТВА КАБЕЛЕЙ}

Благодаря возможностям современных информационных систем показаны пути совершенствования систем параметрической идентификации, а именно, получение более точных оценок параметров математической модели исследуемого объекта с ограниченных во времени и диапазоне, зашумленных выборок данных. Рассмотренный метод идентификации предложено использовать в адаптивных системах управления процессом изготовления высоковольтных электрических кабелей.

ключевые слова: параметрическая идентификация, интегрированный метод идентификации, электротехнические системы, электрические кабели.

Ostroverkhov Mykola, Doctor of Technical Sciences, Professor, Head of the Department of Theoretical Electrical Engineering, National Technical University of Ukraine «Igor Sikorsky Kyiv Polytechnic Institute», Ukraine, e-mail: n.ostroverkhov@hotmail.com, ORCID: http://orcid.org/0000-0002-7322-8052

Silvestrov Anton, Doctor of Technical Sciences, Professor, Department of Theoretical Electrical Engineering, National Technical University of Ukraine «Igor Sikorsky Kyiv Polytechnic Institute», Ukraine, e-mail: silvestrovanton@gmail.com, ORCID: http://orcid.org/ 0000-0002-2511-5029

Kryvoboka Galyna, Senior Lecturer, Cycle Commission of Informatics and Computer Technology, Vinnitsa College of the National University of Food Technologies, Ukraine, e-mail: galinakryvoboka@gmail.com, ORCID: http://orcid.org/0000-0002-2011-4182 